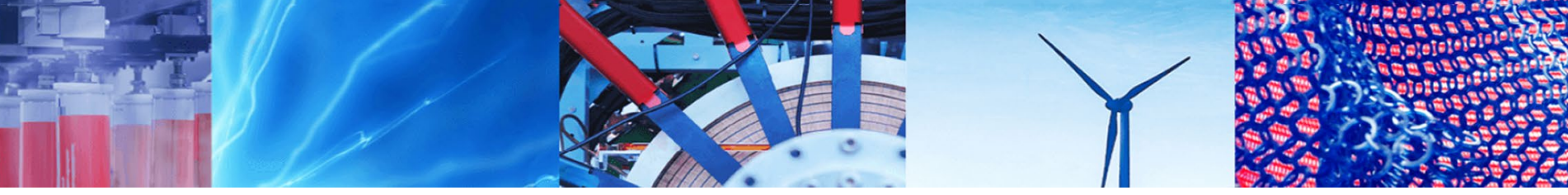

Research Article

\title{
Hydrogel capsules with alfalfa as micronutrients carrier
}

\author{
D. Skrzypczak ${ }^{1} \cdot$ K. Mikula $^{1} \cdot$ A. Witek-Krowiak ${ }^{1}$
}

(c) The Author(s) 2019 OPEN

\begin{abstract}
The aim of this work was to study the properties of biocomposite based on sodium alginate and carboxymethyl cellulose with immobilized alfalfa as a material with controlled release of $\mathrm{Cu}^{2+}$ ions. Physicochemical (swelling, $\mathrm{pH}_{\mathrm{ZPC}}$ ) and sorption (kinetics, equilibrium) properties of the produced structures were investigated. Kinetic data were best described using a general rate law model, and the value of kinetic rate constant was $5.34 \times 10^{-6}$. The sorption kinetics are also described using the Weber-Morris model, and the analysis revealed a three-step sorption. The maximum sorption capacity was determined using the Sips model and amounted to $9 \mathrm{mg} \mathrm{g}^{-1}$. Desorption of $\mathrm{Cu}^{2+}$ ions in soil solution $\left(\mathrm{NaNO}_{3} 1 \mathrm{wt} \%\right)$ was carried out, and biocomposites released micronutrients in a slow way. The results showed that biocomposites with immobilized alfalfa are a very good material for potential applications in the agrochemical industry as a controlled released fertilizer.
\end{abstract}

Keywords Micronutrients $\cdot$ Slow release $\cdot$ Controlled release $\cdot$ Copper $\cdot$ Biosorbent $\cdot$ Alginate

\section{Introduction}

The agrochemical industry is growing rapidly with the population growth. Due to this, the use of chemical soil fertilizers increased significantly in the second half of the twentieth century [1]. The quality of the crop depends mainly on the amount of water and the composition of the soil. Form of micronutrients delivery into the soil has a significant effect on the plant growth. Nutrients are mainly served in the form of synthetic chelates and technical salts. Well-soluble fertilizers are quickly leached from the soil to groundwater. This causes environmental pollution and economic losses associated with the need to fertilize one crop several times per year. For this reason, controlled release fertilizers are more often used, which ensure the release of nutrients during the entire cultivation cycle. Typically, such properties are obtained by coating traditional fertilizers with different polymers. A very important aspect, due to environmental protection, is the degradation of the coating $[2,3]$.
Enriched with microelements biomass can be an alternative to traditional fertilizers. Biosorption processes are commonly used to remove ions from aqueous solutions [4]. Biomass enriched with micronutrients can be used in the agrochemical industry. Increasing the sorption capacity can be achieved by fragmentation of biosorbent and immobilization in hydrogel matrix. Immobilization of the biomaterial also results in obtaining controlled release properties of related micronutrients [5].

The most well-known biopolymer used to immobilize various materials is alginate. This polysaccharide is linear, unbranched copolymer composed of two monomers $\beta$ - $d$ manuranate and $a-1$-guluronate, which are organized in blocks. The most commonly used variant of alginate is the sodium salt of alginic acid. Alginates can form very strong hydrogels by exchanging metal with divalent cations (e.g. $\left(a^{2+}\right)$. The cation reacts with blocks of acidic residues, resulting in the creation of a 3D network [6]. The alginate can be co-polymerized or mixed with other biopolymers such as carboxymethyl cellulose and chitosan. The use of

D. Skrzypczak, dawid.skrzypczak@pwr.edu.pl | 'Department of Chemical Engineering, Faculty of Chemistry, Wroclaw University of Science and Technology, Norwida 4/6, 50-373 Wroclaw, Poland.

SN Applied Sciences (2019) 1:573 | https://doi.org/10.1007/s42452-019-0575-4

Received: 3 February 2019 / Accepted: 6 May 2019 / Published online: 16 May 2019 
an additional component increases the mechanical properties and the sorption capacity of the structures [5].

This paper presents new hydrogel biocomposite based on alginate, carboxymethyl cellulose and alfalfa (Medicago sativa) after supercritical extraction as a new material for controlled release of $\mathrm{Cu}^{2+}$ ions. Copper plays a huge role in the early stages of plant development. It takes part in the photosynthetic transport of electrons, oxidative phosphorylation and immobilization of iron in cells. Its deficiency causes deformation of young leaves and disturbances in the development of generative restrictions. Physicochemical studies of prepared structures were carried out, including swelling properties and $\mathrm{pH}_{\mathrm{ZPC}}$. The sorption capacity of biocomposites was determined using Langmuir, Freundlich and Sips models. Studies on the release of microelements in various media have been carried out.

\section{Materials and methods}

\subsection{Materials}

Sodium alginate (ALG) and carboxymethyl cellulose (CMC) were purchased from Sigma-Aldrich. Copper(II) sulphate $\left(\mathrm{CuSO}_{4}\right)$, calcium chloride $\left(\mathrm{CaCl}_{2}\right)$, acetic acid $\left(\mathrm{CH}_{3} \mathrm{COOH}\right)$ were purchased from POCH (Poland). Alfalfa (Medicago sativa) (A) after supercritical extraction was obtained from a polish producer.

\subsubsection{Preparation of $\mathrm{Cu}^{2+}$ stock solution}

To prepare a solution containing of $1000 \mathrm{mg} \mathrm{L}^{-1} \mathrm{cop}$ per ions, $\mathrm{Cu}\left(\mathrm{SO}_{4}\right)_{2}$ was dissolved in distilled water. Other concentrations were obtained by diluting this stock solution. Hydrochloric acid $(\mathrm{HCl}) 0.1 \mathrm{M}$ and sodium hydroxide $(\mathrm{NaOH}) 0.1 \mathrm{M}$ solution were used to adjust the $\mathrm{pH}$ solution containing of $\mathrm{Cu}^{2+}$ ions.

\subsection{Preparation of beads}

The solution of ALG (2.5 wt \%) and CMC (1.0 wt\%) was prepared by dissolving a known amount of those substances in distilled water at $65^{\circ} \mathrm{C}$. After cooling, $5 \mathrm{wt} \%$ of alfalfa (A) was added to this solution and stirred to complete dissolution. Mixture was dropped into $0.2 \mathrm{M} \mathrm{CaCl}_{2}$ solution (crosslinking solution). The biocomposites were cross-linked for $24 \mathrm{~h}$. After this time, structures were washed and stored in distilled water for future experiments.

\subsection{Analytical measurements}

Biocomposites were observed under the optical microscope (DMi8, LEICA, Germany). The concentration of $\mathrm{Cu}^{2+}$ in the solution was measured with the ICP-OES (inductively coupled plasma-optical emission spectrometry). Mathematical modelling of experimental points was performed using the OriginLab (8 Technology, OriginLab Corporation, USA).

\subsection{Physicochemical properties of biocomposites}

\subsubsection{Swelling properties}

ALG-CMC-A biocomposites ( $1 \mathrm{~g}$ ) were weighted and transferred to four flasks containing $50 \mathrm{~mL} 0.1 \mathrm{M}$ aqueous solution of citric acid, $1 \mathrm{wt} \%$ aqueous solution of sodium chloride $(\mathrm{NaCl})$, water and $1 \mathrm{wt} \%$ aqueous solution of sodium nitrate $\left(\mathrm{NaNO}_{3}\right)$. Next, structures were weighted after 24 , 48 and $96 \mathrm{~h}$. The percentage changes in mass are shown with reference to the zero sample.

\subsection{2 $\mathrm{pH}_{\mathrm{ZPC}}$ : point of zero charge}

ALG-CMC-A capsules $(0.5 \mathrm{~g})$ were weighted and transferred to eight flasks containing $50 \mathrm{~mL} 1 \mathrm{wt} \%$ aqueous solution of $\mathrm{NaCl}$ at the $\mathrm{pH}$ range from 2 to 9 . The samples were left on laboratory shaker for $24 \mathrm{~h}$. After this time, the $\mathrm{pH}$ of the solutions was again measured. The $\mathrm{pH}_{\mathrm{ZPC}}$ was determined by means of a graph $\mathrm{pH}_{24}-\mathrm{pH}_{0}=f\left(\mathrm{pH}_{\text {fixed }}\right)$.

\subsection{Influence of $\mathrm{pH}$ on the process}

Four flasks with $50 \mathrm{~mL}$ aqueous solution with a concentration of $\mathrm{Cu}^{2+}$ ions $200 \mathrm{mg} \mathrm{L}^{-1}$, at the $\mathrm{pH}$ range from 3 to 6 were prepared. ALG-CMC-A biocomposites $(1.5 \mathrm{~g})$ were weighted and transferred to the flasks. The samples were left for $24 \mathrm{~h}$ in an orbital shaker. After this time, the solution was analysed for the $\mathrm{Cu}^{2+}$ ions concentration.

\subsection{Sorption of $\mathrm{Cu}^{2+}$ ions}

\subsubsection{Kinetics}

ALG-CMC-A ( $3 \mathrm{~g})$ were weighted and transferred to flask containing $200 \mathrm{~mL}$ aqueous solution with a concentration of $\mathrm{Cu}^{2+} 200 \mathrm{mg} \mathrm{L}^{-1}(\mathrm{pH} 5)$. The flask was agitated in an orbital shaker. Samples were collected at specific time intervals. Sorption was carried out to achieve equilibrium (24 h).

\subsubsection{Equilibrium}

Six flasks containing $50 \mathrm{~mL}$ aqueous solution with a concentration of $\mathrm{Cu}^{2+}$ ions range from 50 to $500 \mathrm{mg} \mathrm{L}^{-1}(\mathrm{pH}$ 5) were prepared. Biocomposites $(1.5 \mathrm{~g})$ were weighted and transferred to the flasks. The flasks were agitated in 
an orbital shaker for $24 \mathrm{~h}$. After this time, the solution was analysed for the $\mathrm{Cu}^{2+}$ ions concentration.

\subsection{Desorption}

\subsubsection{Enrichment of biocomposites with $\mathrm{Cu}^{2+}$ ions}

Biocomposites were weighed $(15 \mathrm{~g})$ and transferred to $1 \mathrm{~L}$ of the solution containing $\mathrm{Cu}^{2+}$ ions with the concentration of $1000 \mathrm{mg} \mathrm{L}^{-1}$. After $24 \mathrm{~h}$ (sorption equilibrium), the biocomposites were separated and washed several times with distilled water.

\subsubsection{Desorption in various media}

Previously enriched biocomposites ( $3 \mathrm{~g}$ ) were transferred to four flasks containing $100 \mathrm{~mL} 0.1 \mathrm{M}$ aqueous solution of citric acid, $1 \mathrm{wt} \%$ aqueous solution of $\mathrm{NaCl}$, water and $1 \mathrm{wt} \%$ aqueous solution of $\mathrm{NaNO}_{3}$. Desorption was carried out for 14 days. The aqueous solutions were replaced at specific interval times. The solutions were analysed for the $\mathrm{Cu}^{2+}$ ions concentration.

\section{Results and discussion}

\subsection{Physicochemical properties of biocomposites}

\subsubsection{Swelling properties}

The swelling of the prepared structures in various media ( $0.1 \mathrm{M}$ citric acid, $\mathrm{NaCl} 1 \mathrm{wt} \%, \mathrm{NaNO}_{3} 1 \mathrm{wt} \%$ and water) is shown in Fig. 1. Determining the swelling properties is very important for hydrogel structures, especially for release of micronutrients. It has been found that the composites swell most in $\mathrm{NaCl}$ solutions (19 and $22 \%$ after 24 and $48 \mathrm{~h}$ ) and in model soil solution- $-\mathrm{NaNO}_{3}$ (17 and $19 \%$ after 24 and $48 \mathrm{~h}$ ). In both solutions, ion exchange occurs between the $\mathrm{Ca}^{2+}$ ions, present in the composites, and the $\mathrm{Na}^{+}$ions, present in the solution. This causes electrostatic repulsion between $\mathrm{COO}^{-}$groups and thus relaxation of polymer chains. This ultimately leads to degradation of the hydrogel [7]. The swelling promotes the release of ions from the inside of the capsule. In the acidic environment, shrinkage of structures was observed. At a pH lower than 3.65 , the carboxyl groups present in alginate and carboxymethyl cellulose bind to $\mathrm{H}^{+}$ions. The formation of $-\mathrm{COOH}$ groups causes more hydrophobic structures and thereby shrink [8]. The mechanism of shrinking and swelling of biocomposites at low and high pH is shown in Fig. 2.
Fig. 1 Swelling of biocomposites in various media ( $T$ : $20^{\circ} \mathrm{C}$; sorbent dosage $30 \mathrm{~g} \mathrm{~L}^{-1}$; contact time: $96 \mathrm{~h}$; media: aqueous solution of $0.1 \mathrm{M}$ citric acid, $\mathrm{NaCl} 1$ wt\%, $\mathrm{NaNO}_{3} 1$ wt\% and water)

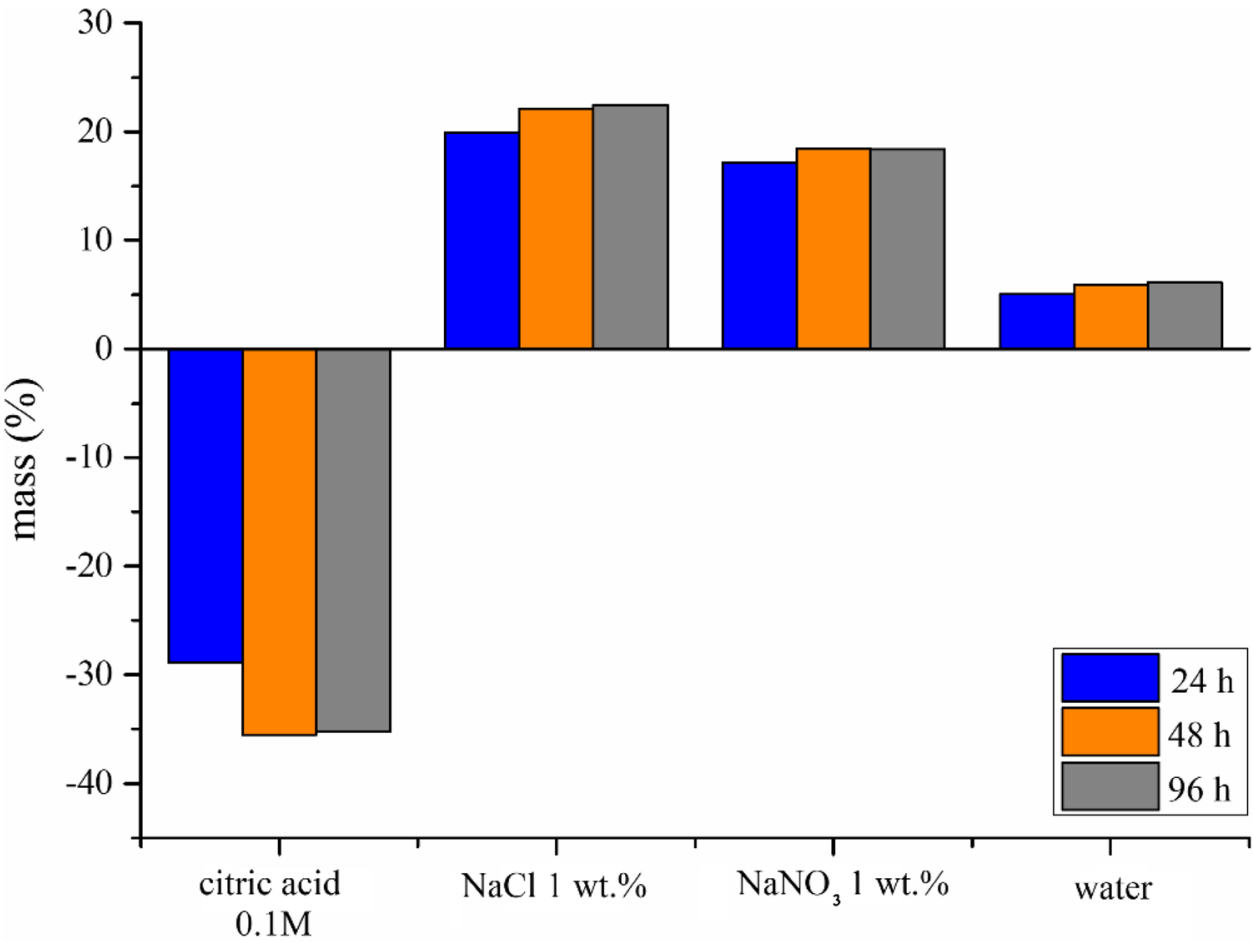

SN Applied Sciences 
Fig. 2 Mechanism of shrinking and swelling of biocomposites at low and high $\mathrm{pH}$

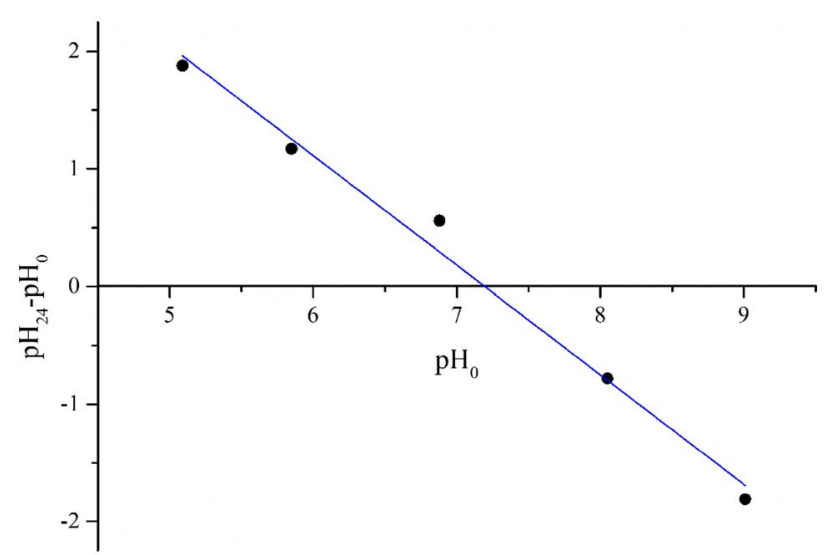

Fig. $3 \mathrm{pH}_{\mathrm{PZC}}$ for biocomposites $\left(T: 20^{\circ} \mathrm{C}\right.$; sorbent dosage $10 \mathrm{~g} \mathrm{~L}^{-1}$; contact time: 24 h; $\mathrm{pH}$ 5-9)

\subsection{2 $\mathrm{pH}_{\mathrm{ZPC}}$ (point of zero charge)}

The $\mathrm{pH}_{\mathrm{ZPC}}$ point is one of the most important parameters, describing the surface properties of a biomass in solution. In this point, the sum of positive and negative charges on the surface is equal to zero, and structures show specific properties. Figure 3 shows the dependence $\mathrm{pH}_{24}-\mathrm{pH}_{0}=f\left(\mathrm{pH}_{\text {fixed }}\right)$. The intersection of the linearized graph is determined by the $\mathrm{pH}_{\mathrm{ZPC}}$ value, which in this case is 7.21. Below $\mathrm{pH}_{\mathrm{ZPC}}$, the sorbent surface is positively charged and the $\mathrm{Cu}^{2+}$ ion sorption decreases. The contribution of $\mathrm{H}^{+}$ions inhibits contact with active sites in the sorbent and metal ions. In contrast, when the $\mathrm{pH}$ is higher surface it has a greater ability to exchange cations [9].

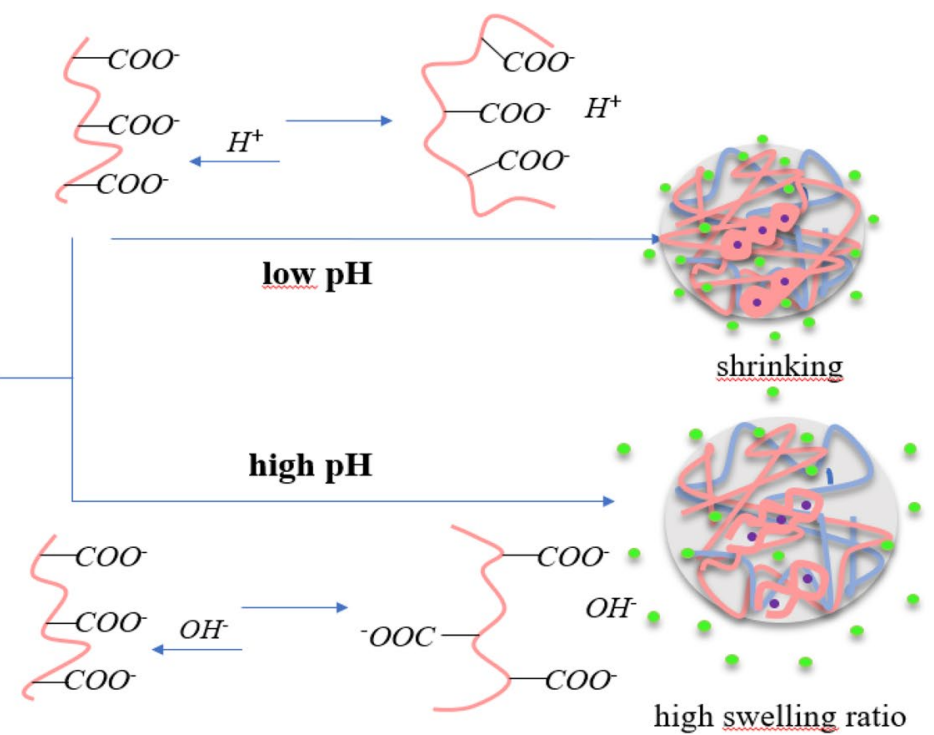

high swelling ratio

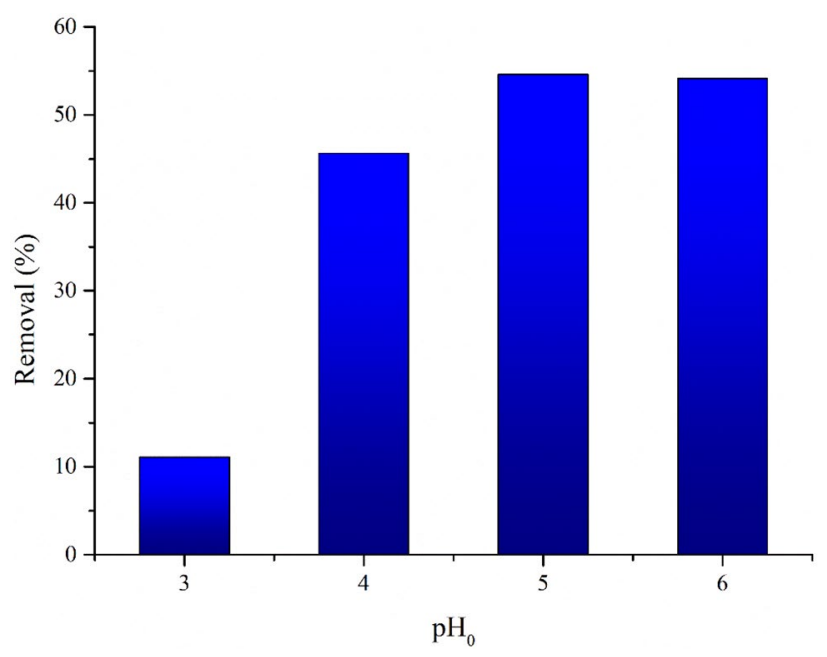

Fig. 4 The influence of $\mathrm{pH}$ on the sorption process $\left(T: 20^{\circ} \mathrm{C}\right.$; sorbent dosage $30 \mathrm{~g} \mathrm{~L}^{-1}$; contact time: $24 \mathrm{~h}$; $\mathrm{pH} 3-6 ; \mathrm{C}_{0}: 200 \mathrm{mg} \mathrm{L}^{-1}$ )

\subsection{Influence of $\mathrm{pH}$ on the process}

The $\mathrm{pH}$ of the solution has a significant effect on the degree of sorbent ionization and determines the surface charge of the sorbent. This makes the parameter have a very important impact on the sorption process. The effect of $\mathrm{pH}$ on the enrichment of composites is shown in Fig. 4. The smallest percentage of enrichment (11\%) was obtained at $\mathrm{pH}$ 3. This is related to existing $\mathrm{H}^{+}$ions competing with $\mathrm{Cu}^{2+}$ ions for active sites in the biocomposite. The best degree of enrichment of the structures (56\%) was obtained in the solution at $\mathrm{pH} 5$. A similar value was obtained in the solution at $\mathrm{pH} 6$. The turbidity of the solution was observed, which may indicate the precipitation of copper in the form of copper(II) 
hydroxide. Subsequent studies were carried out in the solution at $\mathrm{pH} 5$.

\subsection{Uptake kinetics}

In this study, three different kinetics models (pseudo-first order (PFOR) (Eq. 1) [10], pseudo-second order (PSOR) (Eq. 2) [11] and general rate law equation (GRLE) (Eq. 3) [12]) were used to predict kinetics parameters.

$Q_{\mathrm{t}}=Q_{\mathrm{e}} \cdot\left(1-\mathrm{e}^{-k_{1} \cdot t}\right)$

$Q_{\mathrm{t}}=\frac{Q_{\mathrm{e}}^{2} \cdot k_{2} \cdot t}{1+Q_{\mathrm{e}} \cdot k_{2} \cdot t}$

$Q_{\mathrm{t}}=Q_{\mathrm{e}}-\left(Q_{\mathrm{e}}^{1-n}+\left(n_{1}-1\right) \cdot k_{n} \cdot t\right)^{\frac{1}{1-n_{1}}}$

where $Q_{\mathrm{t}}$-the sorption capacity over time, $Q_{\mathrm{e}}$-equilibrium sorption capacity $\left(\mathrm{mg} \mathrm{g}^{-1}\right), k_{1}$-the process rate constant $\left(\mathrm{min}^{-1}\right), k_{2}$ - the process rate constant $\left(\mathrm{g} \mathrm{mg}^{-1}\right.$ $\left.\mathrm{min}^{-1}\right), k_{n}$ - the process rate constant $\left(\mathrm{g} \mathrm{mg}^{-1} \mathrm{~min}^{-1}\right)$, and the $n_{1}$-order rate of the reaction.

In order to investigate the mechanism of sorption of $\mathrm{Cu}^{2+}$ ions on the biocomposite, experimental data were described with the Weber-Morris intramolecular diffusional model (Eq. 4) [13].

$Q_{\mathrm{t}}=k_{\mathrm{p}} \cdot t^{\frac{1}{2}}+C$

where $k_{\mathrm{p}}$-the rate of intra-particle diffusion $\left(\mathrm{mmol} \mathrm{g}{ }^{-1} \min ^{-0.5}\right)$ and $\mathrm{C}$ - constant (-).

Figure 5 a shows the profile of the kinetics of $\mathrm{Cu}^{2+}$ ions sorption on the biocomposite. The cation-binding process takes place most intensively for $30 \mathrm{~min}$. It is caused by a large number of active sites in biocomposite at the beginning of sorption. Then, the process slows down significantly. $\mathrm{Cu}^{2+}$ ions are transported from the surface of the composite into the interior of the hydrogel matrix. In the last stage, adsorption of cations on the surface of immobilized biomass takes place. This stage is the longest and lasts $21 \mathrm{~h}$.

PFOR, PSOR and GRLE models were used to determine the kinetic parameters (Table 1). These models have been designed to describe sorption in homogeneous systems. However, they are used to predict the rate of the process in hydrogels [14]. The fit to the experimental data is shown in Fig. $4 a$. The kinetics of the process were best described by the GRLE model, where the correlation coefficient was 0.999 . The best fit of this model results from the three parameters present in the model. The expected sorption capacity was
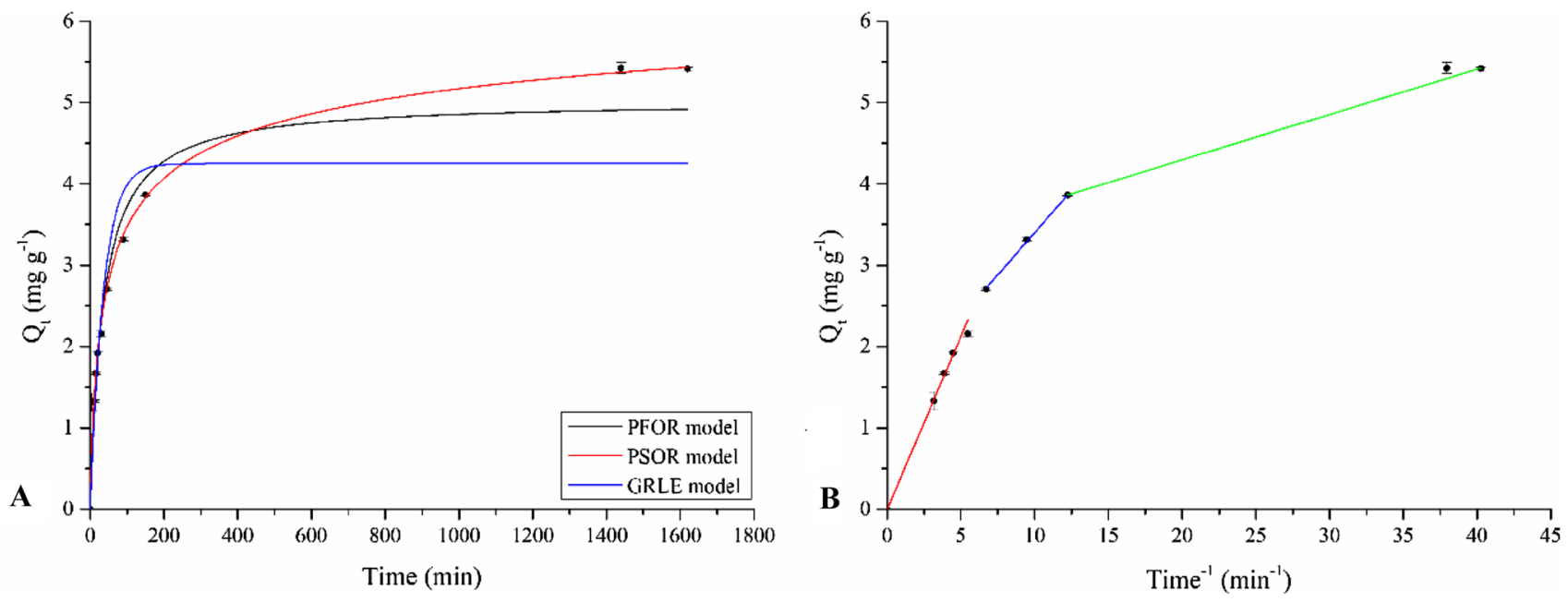

Fig. 5 Kinetics of binding of $\mathrm{Cu}^{2+}$ for biocomposites: dashed line-PFORE, PSORE and GRLE model (a) and dashed line-Weber-Morrison model) (b) ( $T: 20^{\circ} \mathrm{C}$; sorbent dosage $30 \mathrm{~g} \mathrm{~L}^{-1}$; contact time: $\left.26 \mathrm{~h} ; \mathrm{pH} \mathrm{5;} \mathrm{C}_{0}: 200 \mathrm{mg} \mathrm{L}^{-1}\right)$

Table 1 Analysis of PFOR, PSOR and GRLE adsorption kinetics parameters for biocomposites by nonlinear regression method

\begin{tabular}{|c|c|c|c|c|c|c|c|c|c|}
\hline \multicolumn{3}{|l|}{ PFOR } & \multicolumn{3}{|l|}{ PSOR } & \multicolumn{4}{|l|}{ GRLE } \\
\hline$k_{1}\left(\min ^{-1}\right)$ & $Q_{\mathrm{e}}\left(\mathrm{mg} \mathrm{g}^{-1}\right)$ & $R^{2}$ & $k_{2}\left(\mathrm{dm}^{3} \mathrm{~mol}^{-1} \mathrm{~min}^{-1}\right)$ & $Q_{\mathrm{e}}\left(\mathrm{mg} \mathrm{g}^{-1}\right)$ & $R^{2}$ & $k_{n}$ & $n$ & $Q_{\mathrm{e}}\left(\mathrm{mg} \mathrm{g}^{-1}\right)$ & $R^{2}$ \\
\hline $2.79 \mathrm{E}-03$ & 4.25 & 0.974 & $5.7 \mathrm{E}-03$ & 5.02 & 0.993 & $5.34 \mathrm{E}-06$ & 5.23 & 7.61 & 0.999 \\
\hline $\pm 5.5 \mathrm{E}-04$ & $\pm 02.7 \mathrm{E}-03$ & & $\pm 9.26 \mathrm{E}-05$ & $\pm 2 \mathrm{E}-02$ & & $\pm 9.26 \mathrm{E}-08$ & $\pm 4.79 \mathrm{E}-02$ & $\pm 4.2 \mathrm{E}-02$ & \\
\hline
\end{tabular}


$7.6 \mathrm{mg} \mathrm{g}^{-1}$. The $n$ value determined in this case does not imply physical meaning in this case. The determined reaction rates of the PFOR and PSOR models differ significantly from the one determined by the GRLE model $\left(2.79 \times 10^{-3} \mathrm{~min}^{-1}\right.$, $5.70 \times 10^{-3} \mathrm{dm}^{3} \mathrm{~mol}^{-1} \mathrm{~min}^{-1}, 5.34 \times 10^{-6}$ ).

The Weber-Morris model was used for the following description of the process kinetics. Due to the varied speed of the sorption process over time, data analysis is presented in successive three stages at Fig. $5 \mathrm{~b}$. The parameters determined from the linearization of experimental data are presented in Table 2. The binding of ions in the hydrogel with the immobilized biosorbent can be presented in three transport stages. The first part of linearization-transport of $\mathrm{Cu}^{2+}$ ions to the surface of the biocomposite-the second part of linearization-diffusion inside the polymer matrix and the third part-adsorption on the biomass surface. Each subsequent stage of sorption is longer. The copper ions are incorporated into the biocomposite, and this makes it difficult to transport subsequent cations.

\subsection{Sorption isotherms}

Isotherms are of key importance in the description of sorption processes; they are necessary to obtain the data needed to design the installation, e.g. sorption capacity. Three adsorption isotherm models (Langmuir, Freundlich and Sips, Eqs. 5-7) [14-16] were applied to describe the experimental data. The Langmuir model assumes that the adsorption takes place on a completely homogeneous surface with negligible interaction between the adsorbed components, the Freundlich isotherm determines the heterogeneity of the adsorption system, and the Sips model is a combination of the two mentioned models.

$Q_{\mathrm{e}}=Q_{\max } \cdot \frac{K_{\mathrm{b}} \cdot C_{\mathrm{e}}}{1+K_{\mathrm{b}} \cdot C_{\mathrm{e}}}$

$Q_{e}=K_{\mathrm{F}} \cdot C_{\mathrm{e}}^{\frac{1}{n_{\mathrm{F}}}}$

$Q_{e}=Q_{\max } \cdot \frac{K_{\mathrm{s}} \cdot C_{\mathrm{e}}^{\frac{1}{n_{s}}}}{1+K_{\mathrm{s}} \cdot C_{\mathrm{e}}^{\frac{1}{n_{s}}}}$ where $C_{\mathrm{e}}$-the equilibrium concentration of metal ions in the solution $\left(\mathrm{mg} \mathrm{g}^{-1}\right), Q_{\max }$ - the maximum sorption capacity of sorbent $\left(\mathrm{mg} \mathrm{g}^{-1}\right), K_{\mathrm{b}}$ - the Langmuir constant related to sorption affinity $\left(\mathrm{L} \mathrm{mg}^{-1}\right), K_{\mathrm{F}}$-the Freundlich constant related to uptake capacity $\left(\left(\mathrm{mg} \mathrm{g}^{-1}\right)\left(\mathrm{L} \mathrm{mg}^{-1}\right) 1 \mathrm{n}^{-1}\right), n_{\mathrm{F}} n_{\mathrm{S}}-$ the constant known as sorbent intensity $(-)$, and $K_{S}$ - the Sips constant related to sorption affinity $\left(\mathrm{L} \mathrm{mg}^{-1}\right)$.

The values of the correlation coefficient $R^{2}$ calculated from the adsorption models clearly indicate that the Langmuir model provides a better fit to the experimental data than the Freundlich model (Fig. 6; Table 3). The maximum adsorption capacity for $\mathrm{Cu}^{2+}$ ions is $10.97 \mathrm{mg} / \mathrm{g}$. According to the highest correlation coefficient $\left(R^{2}>0.999\right)$, sorption onto hydrogel biocomposite is best described by the Sips model, mainly because it is a three-parameter model. The determined maximum sorption capacity does not differ significantly from the parameters determined by the Langmuir equation. According to the theory, the determined parameter $n s$ decreases with the increase in the number of sorbent components. Values ns closer to zero are related to the heterogeneity of the surface, and close to unity with relatively homogeneous places on the sorbent [14].

Calcium alginate contains two different types of ion binding sites. They are associated with different configurations of polymer chains - $G$ (guluronic acid) and $M$ (mannuronic acid) blocks. $M$ blocks are more readily available for ions, and hydroxyl groups are also present on polymer chains, which also interact with the ions bonded [17]. The complex structure of the biocomposite, enriched with the presence of biomass in the hydrogel structure, can be clearly classified into a specific group of sorbents, which could be easily described by one type of equilibrium model.

\subsection{Desorption in various media}

The release of $\mathrm{Cu}^{2+}$ ions is shown in Fig. 6. After first $24 \mathrm{~h}$, the largest percentage of desorption was observed in citric acid. In the acidic environment, the bonds between the carboxyl group and hydrogen are loosened. A much smaller degree of desorption was observed in the soil solution $\mathrm{NaNO}_{3}$. In Fig. 7, it can be observed that the release of ions increases during the desorption process. Sodium ions interact electrostatically with negatively charged carboxylic groups in the polysaccharide. The ionic strength causes

Table 2 Analysis of Weber-Morris model parameters for biocomposites by linear regression method

\begin{tabular}{|c|c|c|c|c|c|c|c|c|c|c|c|}
\hline \multicolumn{4}{|c|}{ First part of linearization } & \multicolumn{4}{|c|}{ Second part of linearization } & \multicolumn{4}{|c|}{ Third part of linearization } \\
\hline$t(\min )$ & $k_{\mathrm{s}}\left(\mathrm{mg} \mathrm{g}^{-1} \min ^{0,5)}\right.$ & $C$ & $R^{2}$ & $t(\min )$ & $k_{\mathrm{s}}\left(\mathrm{mg} \mathrm{g}^{-1} \min ^{0,5}\right)$ & $C$ & $R^{2}$ & $t(\min )$ & $k_{\mathrm{s}}\left(\mathrm{mg} \mathrm{g}^{-1} \min ^{0,5}\right)$ & $C$ & $R^{2}$ \\
\hline 0 & 0.425 & $6.35 \mathrm{E}-05$ & 0.999 & 45 & 0.208 & 1.329 & 0.999 & 150 & 0.055 & 3.179 & 0.998 \\
\hline 30 & $\pm 1.24 \mathrm{E}-03$ & $\pm 4.78 \mathrm{E}-07$ & & 150 & $\pm 2.78 \mathrm{E}-03$ & $\pm 1.2 \mathrm{E}-02$ & & 1620 & $\pm 5.21 \mathrm{E}-04$ & \pm 0.024 & \\
\hline
\end{tabular}


Fig. 6 Equilibrium of binding of $\mathrm{Cu}^{2+}$ ions for biocomposites (dashed line: Langmuir, Freundlich and Sips model; $T$ : $20^{\circ} \mathrm{C}$; sorbent dosage: $30 \mathrm{~g} \mathrm{~L}^{-1}$, contact time: $24 \mathrm{~h} ; \mathrm{pH} 5 ; \mathrm{C}_{0}$ : 50-500 $\mathrm{mg} \mathrm{L}^{-1}$ )

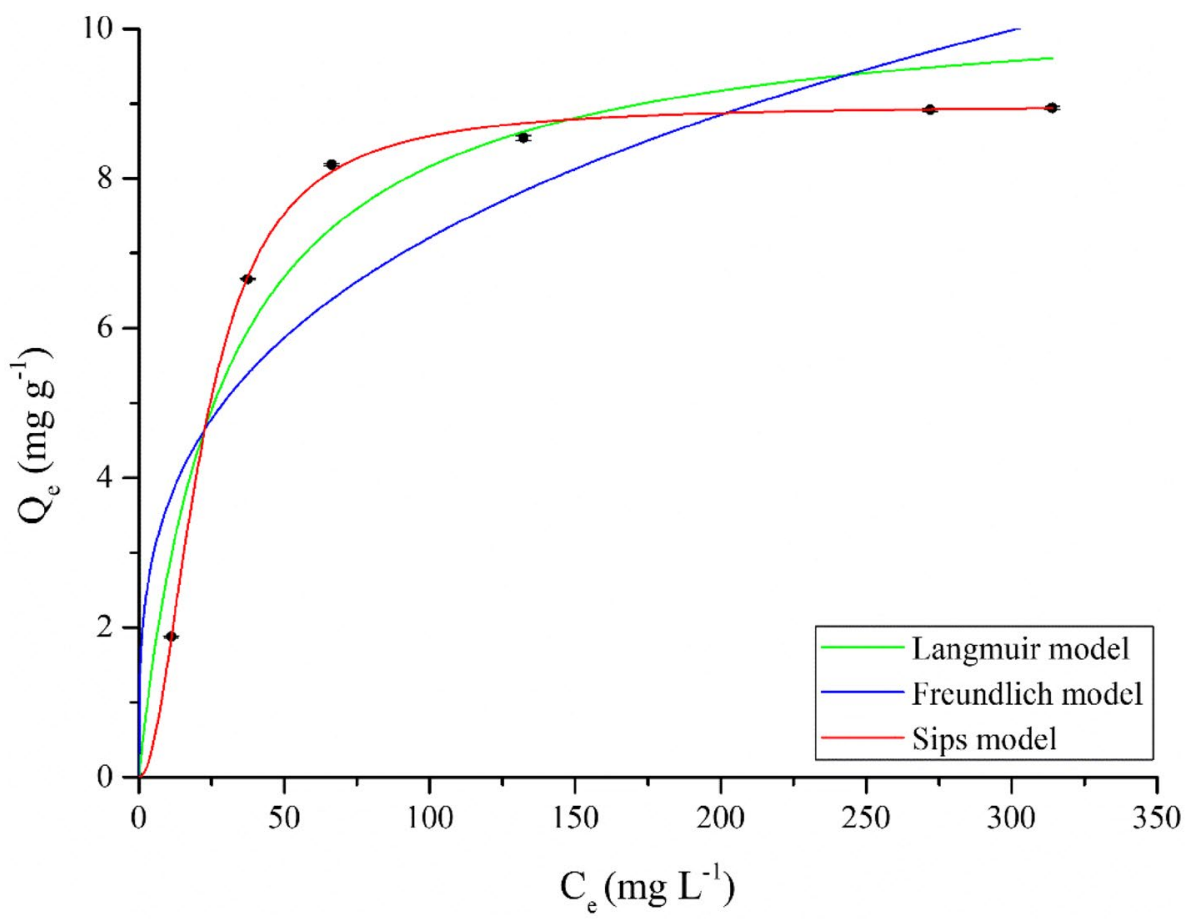

Table 3 Analysis of Langmuir, Freundlich and Sips sorption isotherm parameters for biocomposites by nonlinear regression method

\begin{tabular}{|c|c|c|c|c|c|c|c|c|c|}
\hline \multicolumn{3}{|l|}{ Langmuir } & \multicolumn{3}{|l|}{ Freundlich } & \multicolumn{4}{|l|}{ Sips } \\
\hline$Q_{\max }(\mathrm{mg} / \mathrm{g})$ & $K_{\mathrm{L}}\left(\mathrm{dm}^{3} / \mathrm{mg}\right)$ & $R^{2}$ & $\overline{K_{\mathrm{F}}}$ & $n_{\mathrm{F}}$ & $R^{2}$ & $Q_{\max }(\mathrm{mg} / \mathrm{g})$ & $K$ & $n$ & $R^{2}$ \\
\hline 10.97 & $3.18 \mathrm{e} 2$ & 0.964 & 1.70 & 3.13 & 0.925 & 8.99 & $2 e-3$ & 1.99 & 0.999 \\
\hline $\pm 1.29 \mathrm{e}-01$ & $\pm 1.01 \mathrm{e}-04$ & & $\pm 8.1 \mathrm{e}-02$ & $\pm 1.0 \mathrm{e}-02$ & & $\pm 7.9 \mathrm{e}-02$ & $\pm 2.96 \mathrm{e}-05$ & $\pm 5.09 \mathrm{e}-03$ & \\
\hline
\end{tabular}

Fig. 7 Release of $\mathrm{Cu}^{2+}$ ions in various media for biocomposites $\left(T: 20^{\circ} \mathrm{C}\right.$; sorbent dosage $15 \mathrm{~g} \mathrm{~L}^{-1}$; contact time: 7 days; media: aqueous solution of citric acid $0.1 \mathrm{M}, \mathrm{NaCl} 1 \mathrm{wt} \%$, $\mathrm{NaNO}_{3} 1 \mathrm{wt} \%$ and water)

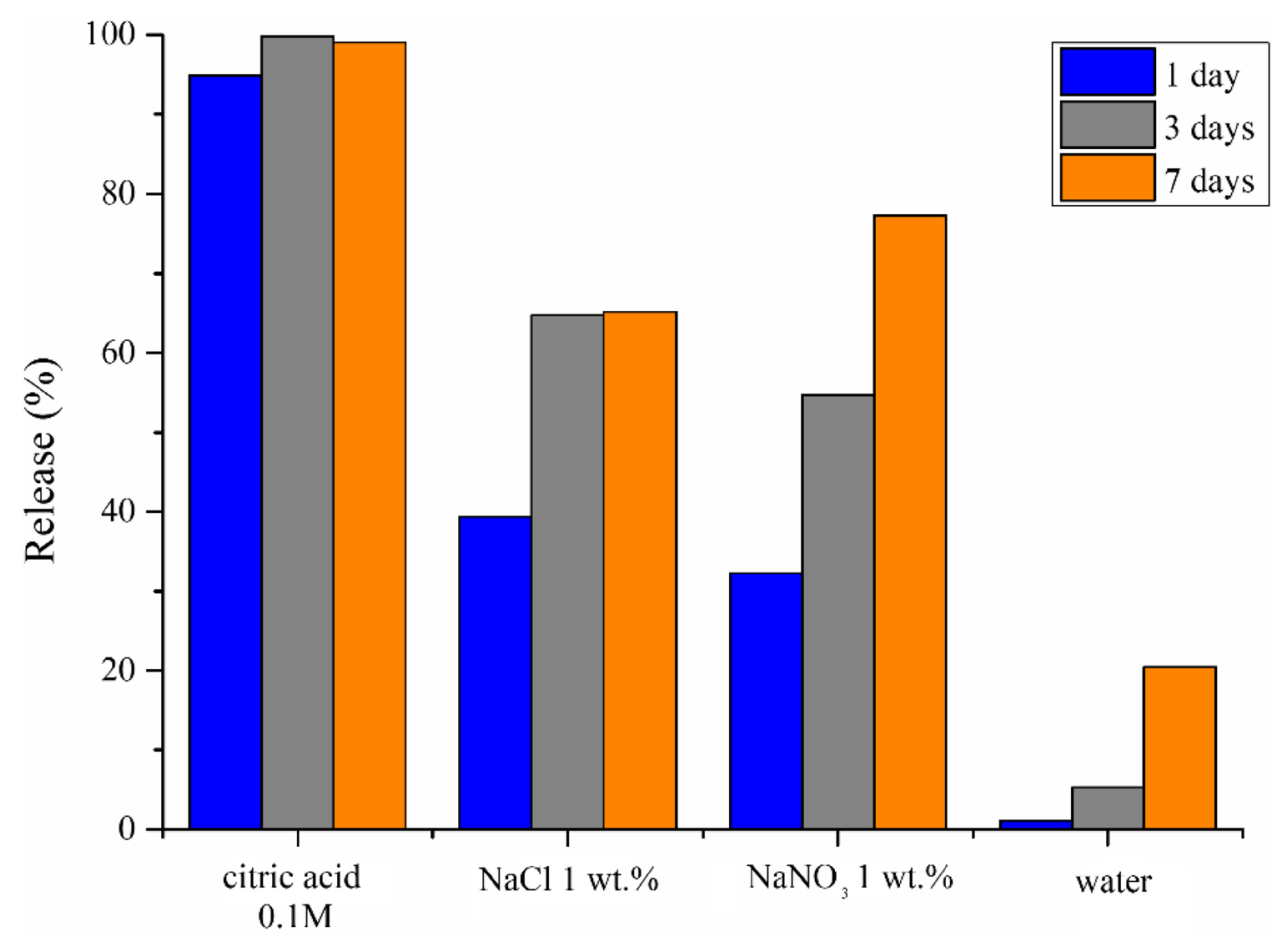


the formation of negative charges along the polymer chains. This leads to slow degradation of the composite, which is closely related to the slow release of $\mathrm{Cu}^{2+}$ cations [18]. The slowest release rate was observed in water. In this case, the only driving force of desorption is the difference in ion concentrations in the medium and in the composite. The increasing percentage of ion release is closely related to the swelling of structures and the greater possibility of cation transport from the interior of the polymer matrix.

\subsection{Future perspectives}

The development of the agrochemical sector for fertilizers with controlled release of micronutrients is a challenge for scientists all around the world. Solutions are sought to increase the efficiency of fertilizers while reducing their costs. Traditional fertilizers are available in the form of synthetic chelates and technical salts. Unfortunately, the forms of this type of fertilizer are very soluble in water. This causes micronutrients leakage to groundwater, which generates economic losses but also environmental hazards. An alternative to traditional fertilizers and the solution to this problem are fertilizers with precise adjustment of the dose of micronutrients at a given stage of plant development. Composite granules presented in the work create a great potential as a bio-fertilizer with controlled release of micronutrients. One of the substrates is waste after extraction, which significantly reduces the cost of preparing composites. The remaining substrates are relatively inexpensive, and the production process can be transferred on an industrial scale. Market introduction would require conducting research directly related to the effect of fertilizer on plant growth.

\section{Conclusion}

Immobilization of biomass had a positive effect on the sorption properties of the material and to obtain a controlled release of $\mathrm{Cu}^{2+}$ ions from the composite. The optimal $\mathrm{pH}$ of the solution for enriching biocomposites was 5. The kinetics of sorption of $\mathrm{Cu}^{2+}$ ions is three-stage, and each subsequent stage is characterized by a lower rate of diffusion of micronutrients inside the matrix. Equilibrium of sorption process was best described by the Sips model. The maximum sorption capacity of the biocomposite was $9 \mathrm{mg} \mathrm{g}^{-1}$. Biocomposites released micronutrients in a slow way in soil solution. The results showed that biocomposites with immobilized alfalfa are a very good material for potential applications in the fertilizer industry.

Acknowledgements This project is financed in the framework of grant entitled: "Cultivated plants and natural products as a source of biologically active substances assign to the production of cosmetic and pharmaceutical products as well as diet supplements" (No. BIOSTRATEG2/298205/9/NCBR/2016) attributed by the National Centre for Research and Development.

\section{Compliance with ethical standards}

Conflict of interest The authors declare that they have no conflict of interest.

Open Access This article is distributed under the terms of the Creative Commons Attribution 4.0 International License (http:// creativecommons.org/licenses/by/4.0/), which permits unrestricted use, distribution, and reproduction in any medium, provided you give appropriate credit to the original author(s) and the source, provide a link to the Creative Commons license, and indicate if changes were made.

\section{References}

1. Davidson D, Gu FX (2012) Materials for sustained and controlled release of nutrients and molecules to support plant growth. J Agric Food Chem 60:870-876

2. Oliet J, Planelles R, Segura ML, Artero F, Jacobs DF (2004) Mineral nutrition and growth of containerized Pinus halepensis seedlings under controlled-release fertilizer. Sci Hortic 103:113-129

3. Kubeck D, Hofmann M, Mayr J, Haring M (2015) Evaluation of the nitroaldol reaction in the presence of metal ioncrosslinked alginates. New J Chem 39:2306-2315

4. Chojnacka K (2005) Biosorption of $\mathrm{Cr}^{3+}, \mathrm{Cd}^{2+}$ and $\mathrm{Cu}^{2+}$ ions by blue-green algae Spirulina sp.: kinetics, equilibrium and the mechanism of the process. Chemosphere 59:75-84

5. Wang Y, Liu M, Ni B, Xie L (2012) K-Carrageenan-sodium alginate beads and superabsorbent coated nitrogen fertilizer with slow-release, water-retention, and anticompaction properties. Ind Eng Chem Res 51:1413-1422

6. Fiol N, Escudero C, Poch J, Villaescusa I (2006) Preliminary studies on $\mathrm{Cr}(\mathrm{VI})$ removal from aqueous solution using grape stalk wastes encapsulated in calcium alginate beads in a packed bed up-flow column. React Funct Polym 66:795-807

7. Bajpai SK, Sharma S (2004) Investigation of swelling/degradation behaviour of alginate beads crosslinked with $\mathrm{Ca}_{2}+$ and $\mathrm{Ba}_{2}+$ ions. React Funct Polym 59(2):129-140

8. Rizwan $\mathrm{M}$ et al (2017) pH sensitive hydrogels in drug delivery: brief history, properties, swelling, and release mechanism, material selection and applications. Polymers (Basel) 9(4):137

9. Trochanowska J, Kowalczuk PB (2014) Punkt zerowego ładunku elektrycznego powierzchni łupka miedzionośnego w roztworze wodnym. Łupek Miedzionośny 1978:61-64

10. Lagergren S (1898) Zur theorie der sogenannten adsorption gelöster stoffe. Handl 24:1-39

11. Ho YS, McKay G (1999) Pseudo-second order model for sorption processes. Process Biochem 34(5):451-465

12. Mata YN, Blázquez ML, Ballester A, González F, Muñoz JA (2009) Biosorption of cadmium, lead and copper with calcium alginate xerogels and immobilized Fucus vesiculosus. J Hazard Mater 163(2-3):555-562

13. Weber JC, Morris WJ (1963) Kinetics of adsorption on carbon from solutions. J Sanit Eng Div 89:31-39 
14. Benettayeb A, Guibal E, Morsli A, Kessas R (2017) Chemical modification of alginate for enhanced sorption of $\mathrm{Cd}(\mathrm{II}), \mathrm{Cu}$ (II) and $\mathrm{Pb}$ (II). Chem Eng J 316:704-714

15. Freundlich H (1907) Über die Adsorption in Lösungen. Zeitschrift für Phys. Chemie 57U(1)

16. Sips R (1948) On the structure of a catalyst surface. J Chem Phys 16(5):490-495

17. Klibthong S, Agbenyega JS (2018) Exploring professional knowing, being and becoming through inclusive pedagogical approach in action (IPAA) framework. Aust J Teachnol Educ 43(3):109-123
18. Matyash M, Despang F, Ikonomidou C, Gelinsky M (2014) Swelling and mechanical properties of alginate hydrogels with respect to promotion of neural growth. Tissue Eng $C$ Methods 20(5):401-411

Publisher's Note Springer Nature remains neutral with regard to jurisdictional claims in published maps and institutional affiliations. 